\title{
Nasopharyngoscopic evaluation of oral appliance therapy for obstructive sleep apnoea
}

\author{
A.S.L. Chan*\#,ף, R.W.W. Lee*,\#,ף, V.K. Srinivasan+, M.A. Darendeliler', \\ R.R. Grunstein ${ }^{\#}$ and P.A. Cistulli*,\#,
}

ABSTRACT: This study aimed to explore the effect of mandibular advancement splints (MAS) on upper airway anatomy during wakefulness in obstructive sleep apnoea (OSA).

Patients commencing treatment for OSA with MAS were recruited. Response to treatment was defined by $a \geqslant 50 \%$ reduction in the apnoea/hypopnoea index. Nasopharyngoscopy was performed in the supine position.

Nasopharyngoscopy was performed in 18 responders and 17 nonresponders. Mandibular advancement caused an increase in the calibre of the velopharynx (mean \pm SEM $+40 \pm 10 \%$ ), with relatively minor changes occurring in the oropharynx and hypopharynx. An increase in crosssectional area of the velopharynx with mandibular advancement occurred to a greater extent in responders than nonresponders $(+56 \pm 16 \%$ versus $+22 \pm 13 \% ; p<0.05)$. Upper airway collapse during the Müller manoeuvre, relative to the baseline cross-sectional area, was greater in nonresponders than responders in the velopharynx $(-94 \pm 4 \%$ versus $-69 \pm 9 \% ; p<0.01)$ and oropharynx (-37 $\pm 6 \%$ versus $-16 \pm 3 \%$; $p<0.01)$. When the Müller manoeuvre was performed with mandibular advancement, airway collapse was greater in nonresponders than responders in the velopharynx (-80 $\pm 11 \%$ versus $+9 \pm 37 \% ; p<0.001)$, oropharynx $(-36 \pm 6 \%$ versus $-20 \pm 5 \% ; p<0.05)$ and hypopharynx $(-64 \pm 6 \%$ versus $-42 \pm 6 \% ; \mathrm{p}<0.05)$.

These results indicate that velopharyngeal calibre is modified by MAS treatment and this may be useful for predicting treatment response.

\section{KEYWORDS: Mandibular advancement splints, nasopharyngoscopy, obstructive sleep apnoea}

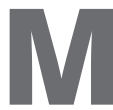
andibular advancement splints (MAS) are an alternative to continuous positive airway pressure (CPAP) for the treatment of obstructive sleep apnoea (OSA) [1]. Although CPAP is the treatment of choice for OSA, its obtrusive nature limits its clinical effectiveness. MAS are an efficacious treatment for OSA in $60-70 \%$ of patients [2]. They are a simpler form of treatment and are often considered by patients to be more acceptable compared to CPAP [3].

The clinical practice parameters of the American Academy of Sleep Medicine recommend the use of MAS for the treatment of mild-to-moderate OSA; or for patients with severe OSA who are unable to tolerate or refuse treatment with CPAP [4]. Treatment of OSA with MAS has been shown to have a beneficial impact on a number of important clinical end-points, including the polysomnographic indices of OSA $[5,6]$, subjective and objective measures of sleepiness [5-7], blood pressure [8-11], aspects of neuropsychological functioning $[8,12]$ and quality of life [8].

MAS mechanically protrude the mandible with the aim of preventing collapse of the upper airway during sleep [1]. However, the mechanisms by which MAS improve OSA are not well understood and little is known about the effect of mandibular advancement on the anatomy of the upper airway. Nasopharyngoscopic assessment during wakefulness has been shown to be a useful approach to assessing the upper airway $[13,14]$ and response to other treatments, such as uvulopalatopharyngoplasty [15]. The primary aim of the present study was to evaluate the mechanism of action of MAS by assessing their effect on upper airway anatomy using nasopharyngoscopy performed during wakefulness in patients with OSA. As a secondary aim, the potential of this approach for identifying responders and nonresponders was also evaluated. and may be able to predict the presence of OSA

\section{AFFILIATIONS}

${ }^{*}$ Centre for Sleep Health and Research, Dept of Respiratory Medicine, Royal North Shore Hospital, St Leonards,

${ }^{*}$ Woolcock Institute of Medical Research, University of Sydney, +Dept of Orthodontics, Faculty of Dentistry, Sydney Dental Hospital, University of Sydney, and "Dept of Respiratory and Sleep Medicine, St George Hospital, University of New South Wales, Sydney, NSW, Australia.

\section{CORRESPONDENCE}

P.A. Cistulli

Centre for Sleep Health and Research Dept of Respiratory Medicine

Royal North Shore Hospital

St Leonards

NSW 2065

Australia

E-mail: cistullip@med.usyd.edu.au

Received:

May 122009

Accepted after revision: Sept 012009

First published online:

Sept 242009 
Preliminary results of this study have been previously reported in the form of abstracts [16-18].

\section{METHODS}

\section{Subjects}

Patients commencing treatment of OSA with a custom-made MAS were recruited from sleep disorders clinics at two university teaching hospitals: Royal North Shore Hospital (St Leonards, New South Wales, Australia) and St George Hospital (Kogarah, New South Wales). Recruitment aimed to include patients with a broad range of severity of OSA, representative of patients in sleep disorders clinics, so as to allow the comparison of nasopharyngoscopic findings in responders and nonresponders. The specific inclusion criteria were the presence of at least two symptoms of OSA (snoring, witnessed apnoeas, fragmented sleep or daytime sleepiness) and evidence of OSA on polysomnography (apnoea/ hypopnoea index $(\mathrm{AHI}) \geqslant 10$ events $\left.\cdot \mathrm{h}^{-1}\right)$. Patients were excluded if they had periodontal disease, insufficient number of teeth or an exaggerated gag reflex. The study was approved by the institutional ethics committees of the Northern Sydney Central Coast Area Health Service (New South Wales), the Sydney South West Area Health Service (New South Wales), the University of Sydney (New South Wales), the South Eastern Sydney Illawarra Area Health Service (New South Wales), and the University of New South Wales (New South Wales). Written informed consent was obtained from all patients.

\section{MAS}

A custom-made two-piece MAS was used (SomnoDent MAS; SomnoMed Ltd, Crows Nest, New South Wales, Australia), the design features and efficacy of which have previously been published [5, 6, 9, 19-21]. Acclimatisation occurred over a period of $\sim 6-8$ weeks. During this time, the appliance was incrementally titrated until the maximum comfortable limit of mandibular advancement was achieved.

\section{Polysomnography}

Polysomnography, as previously described [6], was performed to confirm the diagnosis of OSA and to determine treatment outcome, and was scored according to standard criteria [22, 23]. Apnoeas were defined by a cessation of airflow for $\geqslant 10 \mathrm{~s}$ in association with oxygen desaturation of $\geqslant 3 \%$ or an arousal. Hypopnoeas were defined by a reduction in the amplitude of airflow, as measured using nasal pressure or thoraco-abdominal wall movement, by $>50 \%$ of the baseline measurement for $\geqslant 10 \mathrm{~s}$, in association with oxygen desaturation of $\geqslant 3 \%$ or an arousal.

\section{Treatment outcome}

The definition of treatment outcome was based on the results of polysomnography, as previously described $[5,6,21]$. "Responders" were defined as patients with a reduction in $\mathrm{AHI}$ of $\geqslant 50 \%$; "nonresponders" were defined as patients with a reduction in AHI of $<50 \%$. This somewhat liberal definition reflects clinical practice, with patients often obtaining clinical benefit despite incomplete resolution of OSA.

\section{Nasopharyngoscopy}

A video-endoscopy system (Olympus Medical Systems Corp., Tokyo, Japan) was used for nasopharyngoscopy. Nasopharyngoscopy was performed by a single operator after the completion of acclimatisation to treatment with MAS and the maximum comfortable limit of mandibular advancement was achieved. It was performed with patients in the supine position and the Frankfort plane perpendicular to horizontal. Prior to the procedure, patients were given instructions for the Müller manoeuvre and given time to practise the manoeuvre until they were comfortable performing it. For the Müller manoeuvre, patients were asked to perform a maximal inspiration against a closed airway. Following the administration of topical anaesthetic nasal spray (4\% lignocaine), the nasopharyngoscope was inserted into the nose and pharynx. Digital images of the velopharynx, oropharynx and hypopharynx were obtained. For each of these segments, images were taken during tidal breathing and the Müller manoeuvre, both with and without mandibular advancement. In order to ensure consistent magnification, the position of the scope, marked at the nares, was maintained when obtaining images for a given airway segment. Visual monitoring during the procedure ensured that an orthogonal view was maintained and captured for subsequent analysis. Mandibular advancement was provided using the patients' custom-made MAS.

The segments of the upper airway were defined by anatomical landmarks. The velopharynx was defined by the level of the uvula, the oropharynx was defined by the base of the tongue and the hypopharynx was defined by the tip of the epiglottis. Video-editing software was used to capture frames from the digital video recording of the nasopharyngoscopy. Image analysis software (Imagej; National Institutes of Health, Bethesda, MD, USA) was used to determine cross-sectional areas of the upper airway lumen. Airway measurements were made using nasopharyngoscopic images captured during quiet tidal breathing and during a maximal Müller manoeuvre, both with and without mandibular advancement. The cross-section of the airway was defined by a manual segmentation process to identify the edge of the airway lumen at specific anatomical landmarks. The quantitative analysis of nasopharyngoscopic images has previously been shown to be a useful approach in the evaluation of the upper airway [14], and we have previously shown (unpublished data) good intra-observer reproducibility using this technique (mean \pm SD coefficient of variation $3.6 \pm 1.3 \%$ ) when making repeated measurements on the same nasopharyngoscopic images. Image analysis was performed without knowledge of the treatment outcome on polysomnography. For the purposes of assessing the association between nasopharyngoscopic findings and the treatment response on polysomnography, an increase in the crosssectional area of the lumen of the upper airway was based on any increase in the quantitative assessment of the crosssectional area on the nasopharyngoscopic images.

\section{Statistical analysis}

Statistical analyses were performed using a statistical software package (SPSS 13.0 for Windows; SPSS, Inc., Chicago, IL, USA). Descriptive statistics for clinical characteristics of patients and cross-sectional areas of the upper airway lumen are presented as mean \pm SD and mean \pm SEM, respectively. Continuous variables were compared using an unpaired t-test or Mann-Whitney Utest, as appropriate. Categorical variables were compared using the Chi-squared test or the Fisher's exact test. Logistical regression analysis was performed using a forward step-wise procedure. Statistical significance was accepted if $\mathrm{p}<0.05$. 


\section{RESULTS}

\section{Clinical characteristics of patients}

35 patients were recruited for this study. Of these patients, 18 were responders and 17 were nonresponders. There was no significant difference between responders and nonresponders in the degree of mandibular advancement (mean \pm SD $5.8 \pm 2.2 \mathrm{~mm}$, representing $75 \%$ of maximum mandibular protrusion). In responders, treatment with MAS resulted in a reduction of AHI to $6.8 \pm 7.9$ events $\cdot h^{-1}$, with $66.7 \%$ of patients achieving a complete response (reduction of $\mathrm{AHI}$ to $<5$ events $\cdot \mathrm{h}^{-1}$ ) and $33.3 \%$ achieving a partial response $(\geqslant 50 \%$ reduction in $\mathrm{AHI}$, but with residual AHI of $\geqslant 5$ events $\cdot h^{-1}$ ). There were no significant differences between responders and nonresponders with respect to age, sex, body mass index or baseline AHI. The clinical characteristics of patients are shown in table 1 .

\section{Nasopharyngoscopy}

Nasopharyngoscopy was performed in all patients. The procedure was generally well tolerated, with no major complications. Imaging of the oropharynx and hypopharynx was not able to be completed in two patients due to exaggerated gag reflexes. A further patient did not have imaging of the oropharynx.

\section{Changes in cross-sectional areas of upper airway lumen Mandibular advancement}

Mandibular advancement increased the velopharyngeal crosssectional area in both responders and nonresponders (mean \pm SEM $+40 \pm 10 \%$ ), with an increase in the lateral dimension of the velopharynx by $+25 \pm 5 \%$ and an increase in the anteroposterior dimension of the velopharyn $x$ by $+17 \pm 6 \%$. However, the extent of the increase in the velopharyngeal cross-sectional area, relative to the baseline cross-sectional area, was significantly greater in responders than nonresponders. Relatively smaller increases in cross-sectional area were produced by mandibular advancement in the oropharynx $(+1.8 \pm 3.1 \%)$ and hypopharynx $(+8.9 \pm 7.1 \%)$, and there were no significant differences in the change in cross-sectional area with mandibular advancement between responders and nonresponders in these segments.

\begin{tabular}{|c|c|c|}
\hline \multirow[t]{2}{*}{ TABLE 1} & \multirow[b]{2}{*}{ Responders ${ }^{\#}$} & \multirow[b]{2}{*}{ Nonresponders } \\
\hline & & \\
\hline Patients n & 18 & 17 \\
\hline Male \% & 77.8 & 82.4 \\
\hline Age yrs & $53.7 \pm 11.9$ & $55.8 \pm 10.1$ \\
\hline $\mathrm{BMI} \mathbf{k g} \cdot \mathrm{m}^{-2}$ & $29.3 \pm 4.7$ & $31.0 \pm 4.6$ \\
\hline Baseline AHI events $\cdot h^{-1}$ & $29.3 \pm 15.7$ & $24.1 \pm 11.2$ \\
\hline AHI with MAS events $\cdot h^{-1}$ & $6.8 \pm 7.9$ & $26.8 \pm 23.9$ \\
\hline Complete responders $\%^{+}$ & 66.7 & \\
\hline \multicolumn{3}{|c|}{$\begin{array}{l}\text { Data are presented as mean } \pm \mathrm{SD} \text {, unless otherwise stated. BMI: body mass } \\
\text { index; } \mathrm{AHI} \text { : apnoea/hypopnoea index; MAS: mandibular advancement splints. } \\
\text { \#: "Responders" were defined as patients with a } \geqslant 50 \% \text { reduction in } \mathrm{AHI} \text {; } \\
\because: \text { "Nonresponders" were defined as patients with a }<50 \% \text { reduction in } \mathrm{AHI} \text {; } \\
+. \text { "Complete responders" were defined as patients with a post-treatment } \mathrm{AHI} \text { of } \\
<5 \text { events } \cdot h^{-1} \text {. }\end{array}$} \\
\hline
\end{tabular}

\section{Müller manoeuvre}

The Müller manoeuvre resulted in collapse of the velopharynx, oropharynx and hypopharynx in both responders and nonresponders. However, the extent of collapse, relative to the baseline cross-sectional area, was significantly greater in nonresponders than responders in the velopharynx and oropharynx. In the hypopharynx, there was no significant difference in the extent of collapse between responders and nonresponders.

\section{Müller manoeuvre with mandibular advancement}

When the Müller manoeuvre was performed with mandibular advancement, the extent of collapse, relative to the baseline cross-sectional area, was significantly greater in nonresponders than responders in the velopharynx, oropharynx and hypopharynx.

The changes in the cross-sectional areas of the velopharynx, oropharynx and hypopharynx with the Müller manoeuvre and mandibular advancement are shown in figures 1, 2 and 3 . Representative nasopharyngoscopic images of the velopharynx from a responder and nonresponder are shown in figures 4 and 5 .

\section{Nasopharyngoscopic findings and treatment outcome}

Increase in cross-sectional area of airway lumen with mandibular advancement

An increase in the velopharyngeal cross-sectional area with mandibular advancement was significantly associated with a treatment response on polysomnography (sensitivity $88.9 \%$, specificity $47.1 \%$, positive predictive value $64.0 \%$, negative predictive value $80.0 \% ; \mathrm{p}<0.05)$. An increase in the crosssectional area of the oropharynx or hypopharynx was not significantly associated with treatment outcome.

\section{Increase in cross-sectional area of airway lumen during Müller manoeuvre with mandibular advancement}

An increase in the cross-sectional area of the airway lumen when the Müller manoeuvre was performed with mandibular advancement (relative to when the Müller manoeuvre was performed without mandibular advancement) was associated with a treatment response on polysomnography for the velopharyngeal

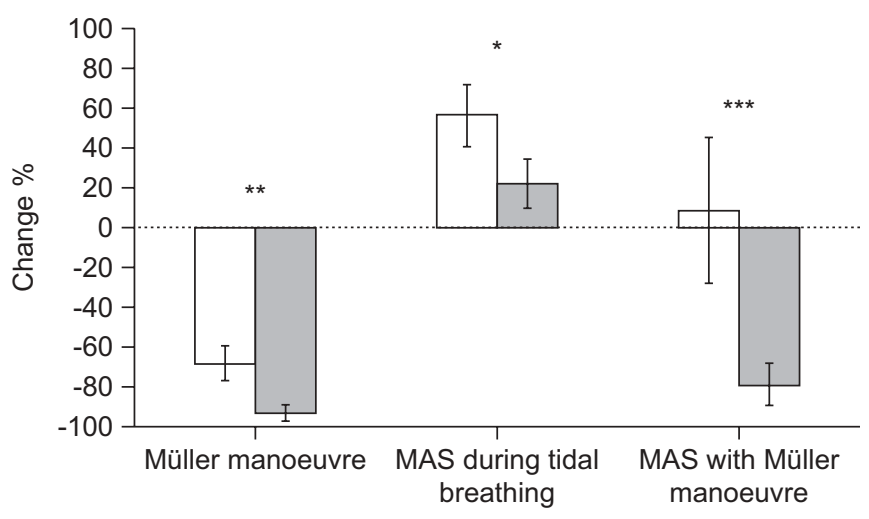

FIGURE 1. The changes in cross-sectional area of the velopharynx with the Müller manoeuvre and mandibular advancement, relative to the baseline crosssectional area. The bars and whiskers represent mean \pm SEM, respectively Responders $(\square)$ : $n=18$; nonresponders $(\square)$ : $n=17$. MAS: mandibular advancement splints. ${ }^{*}: p<0.05 ;{ }^{* *}: p<0.01 ; * * *: p<0.001$ 


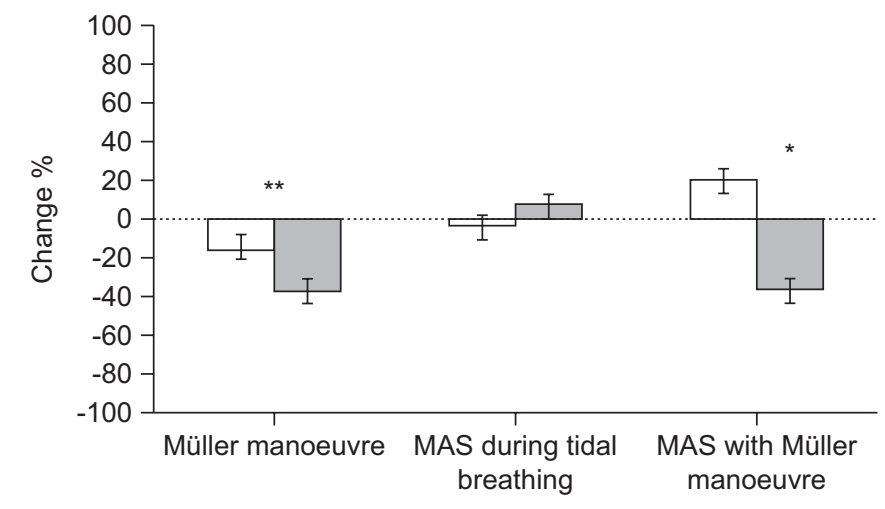

FIGURE 2. The changes in cross-sectional area of the oropharynx with the Müller manoeuvre and mandibular advancement, relative to the baseline crosssectional area. The bars and whiskers represent mean \pm SEM, respectively Responders $(\square)$ : $n=15$; nonresponders $(\square)$ : $n=17$. MAS: mandibular advancement splints. ${ }^{*}: p<0.05 ;{ }^{*}: p<0.01$.

(sensitivity $83.3 \%$, specificity $76.5 \%$, positive predictive value $78.9 \%$, negative predictive value $81.3 \%$; $<<0.001$ ) and hypopharyngeal segments (sensitivity $58.8 \%$, specificity $87.5 \%$, positive predictive value $83.3 \%$, negative predictive value $66.7 \%$; $<<0.01$ ). An increase in the cross-sectional area of the oropharynx when the Müller manoeuvre was performed with mandibular advancement (relative to when the Müller manoeuvre was performed without mandibular advancement) was not significantly associated with treatment outcome.

The association between an increase in the cross-sectional area of the velopharynx when the Müller manoeuvre was performed with mandibular advancement (relative to when the Müller manoeuvre was performed without mandibular advancement) and the treatment response on polysomnography is shown in table 2 . In responders, the mean increase in the velopharyngeal cross-sectional area, in absolute terms, when the Müller manoeuvre was performed with mandibular advancement (relative to when the Müller manoeuvre was performed without mandibular advancement) was mean \pm SEM $+77.8 \pm 32.3 \%$, compared to $+14.2 \pm 9.0 \%$ in nonresponders $(\mathrm{p}<0.05)$. As shown in table 2 , a relative increase of $\geqslant 5 \%$ in the velopharyngeal crosssectional area during the Müller manoeuvre with mandibular advancement (relative to when the Müller manoeuvre was performed without mandibular advancement) was observed in $83.3 \%$ of responders, compared to $23.5 \%$ of nonresponders.

\section{Logistic regression analysis}

These nasopharyngoscopic findings were considered in a logistic regression analysis. This identified an increase in the cross-sectional area of the velopharynx when the Müller manoeuvre was performed with mandibular advancement (relative to when the Müller manoeuvre was performed without mandibular advancement) as a predictor of a treatment response on polysomnography $(\mathrm{p}<0.01)$. The inclusion of other nasopharyngoscopic findings did not significantly improve the prediction model.

\section{Intra-observer reproducibility of nasopharyngoscopic findings}

As the velopharynx was shown to be of importance in the mechanism of action of mandibular advancement and as a

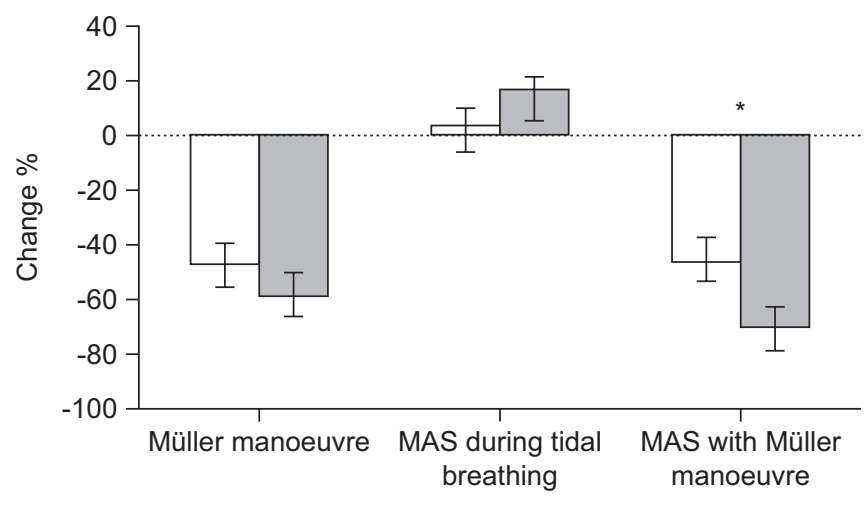

FIGURE 3. The changes in cross-sectional area of the hypopharynx with the Müller manoeuvre and mandibular advancement, relative to the baseline crosssectional area. The bars and whiskers represent mean \pm SEM, respectively. Responders $(\square)$ : $n=16$; nonresponders $(\square)$ : $n=17$. MAS: mandibular advancement splints. *: $p<0.05$.

potential predictor of treatment outcome, the reproducibility of the nasopharyngoscopic evaluation of cross-sectional area of the velopharynx, during tidal breathing and the Müller manoeuvre, was assessed in a random subset of patients in this study $(n=5)$ by assessing the variation of these measurements when repeated by the same operator. The reproducibility was very
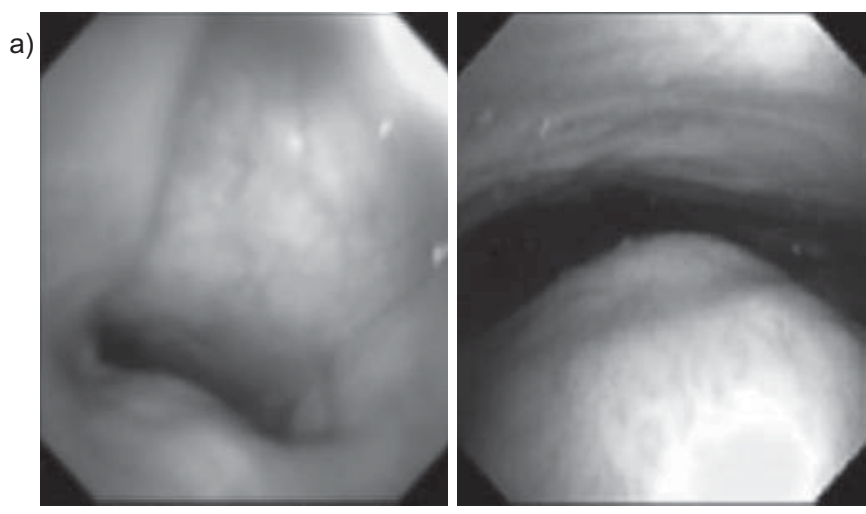

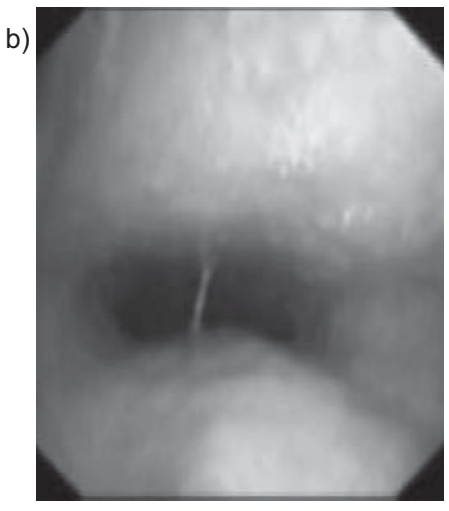

Without MAS

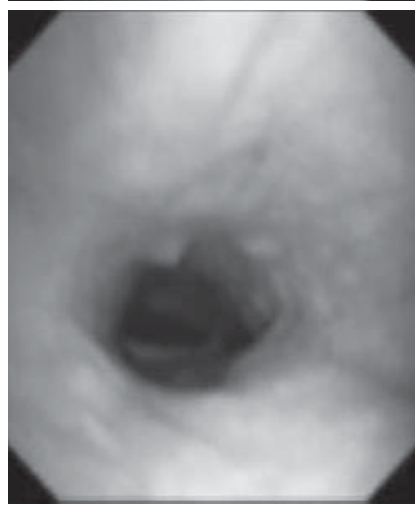

With MAS
FIGURE 4. Representative nasopharyngoscopic images of the velopharynx from a) a responder and b) a nonresponder during tidal breathing. In the responder, mandibular advancement can be seen to increase the calibre of the velopharynx. This effect does not occur in the nonresponder. MAS: mandibular advancement splints. 


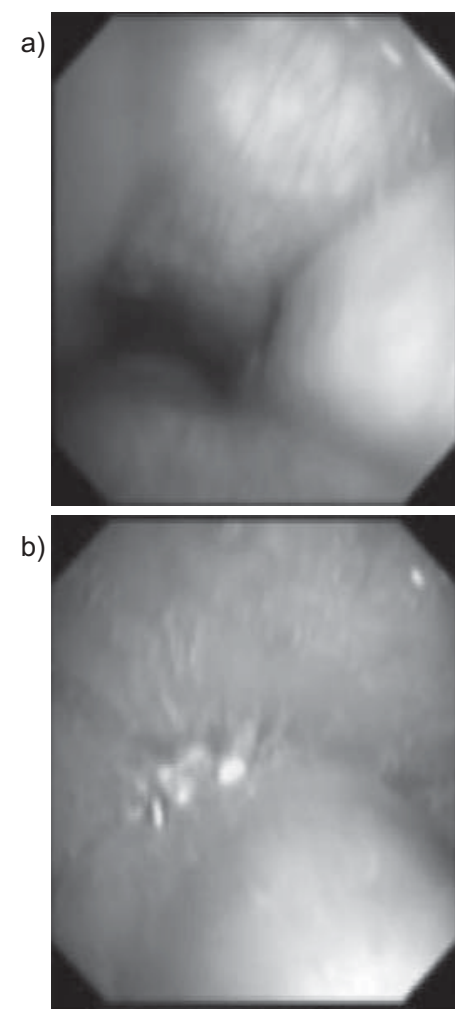

Without MAS
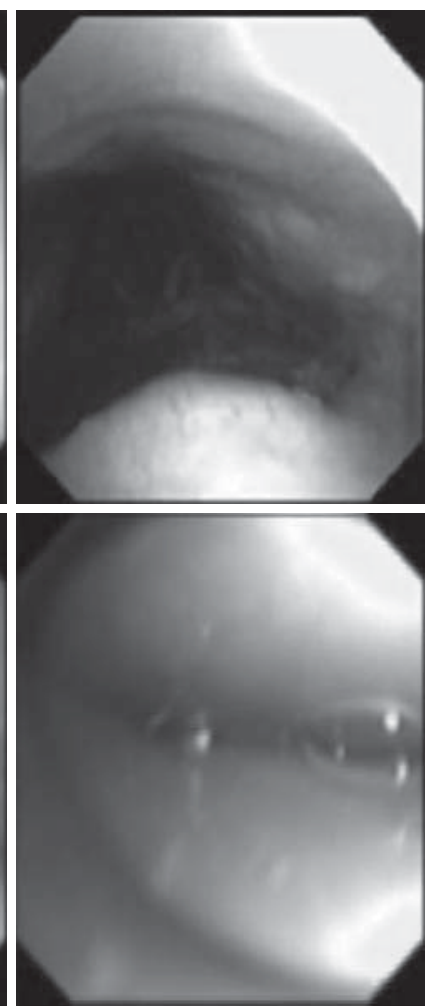

With MAS
FIGURE 5. Representative nasopharyngoscopic images of the velopharynx from a) a responder and b) a nonresponder during the Müller manoeuvre. In the responder, mandibular advancement improves the patency of the velopharynx during the Müller manoeuvre. In the nonresponder, there is persistent velopharyngeal collapse despite mandibular advancement. MAS: mandibular advancement splints.

good, with mean \pm SD coefficients of variation of $7.6 \pm 2.1 \%$ and $5.3 \pm 5.8 \%$ for measurements made during tidal breathing and the Müller manoeuvre, respectively.

\section{DISCUSSION}

There has been increasing evidence to support the use of MAS for the treatment of OSA in clinical practice. Overall, $\sim 60-70 \%$ of patients achieve a reduction of $\geqslant 50 \%$ in AHI, with a reduction of $\mathrm{AHI}$ to $<5$ events $\cdot \mathrm{h}^{-1}$ occurring in $35-40 \%$ of patients [5, 6]. Although less efficacious than CPAP for improving AHI, MAS are a simpler form of treatment and are often considered by patients to be a more acceptable treatment modality [24]. However, the mechanisms by which MAS improve OSA are not well understood and little is known about the actual effect of mandibular advancement on the anatomy of the upper airway.

The key findings of this study are that mandibular advancement causes an increase in the calibre of the velopharynx, with relatively minor changes occurring in the oropharynx and hypopharynx, and that nasopharyngoscopy performed during wakefulness is able to discern anatomical differences in the upper airway between those who respond to treatment with MAS and those who do not. The extent of collapse of the velopharynx and oropharynx during the Müller manoeuvre

TABLE 2 The association between an increase in the
cross-sectional area of the velopharynx when the
Müller manoeuvre was performed with
mandibular advancement (relative to when the
Müller manoeuvre was performed without
mandibular advancement) and the treatment
response on polysomnography

was greater in nonresponders than responders. Mandibular advancement produced a greater degree of increase of the velopharyngeal calibre in responders than nonresponders. When the Müller manoeuvre was performed with mandibular advancement, the extent of collapse of the velopharynx, oropharynx and hypopharynx was greater in nonresponders than responders. The study cohort was typical of a population of OSA patients seen in a sleep disorders clinic, with a broad range of anthropomorphic characteristics and OSA severity, and thus, the results of this study are likely to have good generalisability.

The results of this study suggest that the velopharynx is an important site in the mechanism of action of MAS treatment, consistent with the findings of previous studies [25-27]. These studies, performed in both anaesthetised patients [27] and awake patients with OSA $[25,26]$, found that advancement of the mandible improved the patency of the velopharynx. The effect of mandibular advancement on the velopharyngeal closing pressure has also been shown to be important in achieving control of sleep-disordered breathing [28], and there have been studies indicating that the velopharyngeal segment may be relevant for the prediction of treatment outcome [26, 29]. All of this challenges the traditional notion that the mechanism of action of MAS is to mechanically advance the mandible and produce an increase in oropharyngeal dimensions. The precise reason for this effect on the velopharynx is unclear, but soft tissue structures within the palatoglossal and palatopharyngeal arches connect the mandible, tongue, lateral pharyngeal walls and soft palate. It has been proposed that such soft tissue connections may be stretched by mandibular advancement [30]. These structural changes are associated with a reduction in the collapsibility of the upper airway during sleep [31]. The importance of upper airway neuromuscular reflexes in the mechanism of action of MAS remains uncertain.

Given the anatomical basis of OSA [32], and the differences between responders and nonresponders observed in this study, upper airway imaging has the potential to be useful for predicting treatment outcome. Magnetic resonance imaging (MRI) of the upper airway has previously been used to show that the effect of mandibular advancement on the calibre of the upper airway differs between responders and nonresponders [26]. During the Müller manoeuvre, an improvement in upper airway patency on MRI with mandibular advancement was found to be associated with a successful treatment outcome, 
whereas persistence of upper airway collapse with mandibular advancement was associated with treatment failure [33]. Druginduced "sleep" nasopharyngoscopy has also been used to select patients whose airway patency improves with mandibular advancement for treatment with MAS [34]. The awake nasopharyngoscopic approach used in this study has more direct application to the clinical practice setting.

The standard clinical pathway for commencing treatment with MAS involves an initial medical assessment (including objective confirmation of OSA and its severity), followed by a dental assessment [1]. As not all patients achieve a successful outcome when treated with MAS, the development of a simple and clinically useful tool to predict which patients will respond would aid the appropriate selection of patients. Although there are a number of anthropomorphical, physiological, cephalometrical and polysomnographical parameters that have been associated with a better treatment outcome [6, 19, 21, 29, 3538 , there have been no prospective studies demonstrating the ability to predict the outcome of treatment using these parameters, either singly or in combination. A recent development has been the use of single-night titration of mandibular advancement during sleep to determine the polysomnographic response and the amount of mandibular advancement required to achieve a response [39, 40], but further studies are needed to assess its utility in clinical practice. Nasopharyngoscopy is widely available and easily performed, and could therefore be a useful prediction tool.

In order to have clinical utility, the nasopharyngoscopic findings needed to predict the outcome of treatment with MAS would have to be easily recognisable. In this study, an increase in the velopharyngeal calibre with mandibular advancement, and an increase in the velopharyngeal and hypopharyngeal calibre when the Müller manoeuvre was performed with mandibular advancement (relative to when the Müller manoeuvre was performed without mandibular advancement) were significantly associated with a treatment response on polysomnography. Although a segmentation process with quantification of cross-sectional areas was used to determine the changes in the airway lumen in this study, it is possible that these nasopharyngoscopic findings could be observed in clinical practice by qualitative assessment of crosssectional areas because of the magnitude of the changes. An increase in the velopharyngeal calibre when the Müller manoeuvre was performed with mandibular advancement appeared to have the best performance characteristics, with a positive predictive value of $78.9 \%$ and negative predictive value of $81.3 \%$. This nasopharyngoscopic finding was identified as a predictor of a treatment response in the logistic regression analysis and the inclusion of other nasopharyngoscopic findings did not improve the prediction model. The intra-observer reproducibility of the nasopharyngoscopic assessment of velopharyngeal calibre, during tidal breathing and the Müller manoeuvre, was good.

There are a number of important limitations of this study. There was the potential for selection bias as patients commencing treatment of OSA with a custom-made MAS were recruited, rather than de novo patients with OSA. The higher proportion $(48.6 \%)$ of nonresponders in this study proved useful for examining differences in nasopharyngoscopic findings. The definition of treatment outcome, with response to MAS defined by a reduction in $\mathrm{AHI}$ of $\geqslant 50 \%$, could be criticised for including those who only obtained a partial response. However, we intentionally used this definition because it reflects clinical practice, with patients often obtaining clinical benefit despite incomplete resolution of OSA. The custom-made MAS used in this study was of a single device design, which may limit the extent to which the results can be generalised to other devices. With regard to the nasopharyngoscopy, it is possible that the effect of the Müller manoeuvre could have varied as a result of differences in intraluminal pressure generated by patients. However, the complexity of measuring intraluminal pressure would be a barrier to the use of such a method in clinical practice, so we chose to evaluate a clinically useful method and were able to demonstrate good intra-observer reproducibility. The study was also performed during wakefulness and thus the effects of mandibular advancement observed in this study may not be identical to the changes that occur during sleep. Finally, before such a method can be translated to clinical practice, it needs to be validated in a prospective cohort. This is important as, in this study, mandibular advancement was provided using the custommade MAS. In a prospective study, nasopharyngoscopic prediction would need to be made prior to construction of the MAS. Furthermore, a prediction model would generally be expected to have less predictive value in a validation cohort compared to the original derivation cohort. It would also be important to clarify the effects of inter-observer variability, as a prediction tool that can only be performed by a single operator would not have clinical utility, and assess whether the predictive utility of nasopharyngoscopy can be improved by combining it with other methods, such as flow/volume curves [21].

In conclusion, this study indicates that velopharyngeal calibre is modified by MAS treatment, and that nasopharyngoscopy performed during wakefulness is able to identify anatomical differences in the upper airway between those who respond to treatment with MAS and those who do not. Such a method may have clinical utility in predicting the outcome of treatment of OSA with MAS, and improve the selection of patients for this treatment modality.

\section{SUPPORT STATEMENT}

Supported by the National Health and Medical Research Council of Australia (Medical Postgraduate Scholarship No. 457155).

\section{STATEMENT OF INTEREST}

Statements of interest for M.A. Darendeliler, R.R. Grunstein and P.A. Cistulli, and for the study itself can be found at www.erj.ersjournals. $\mathrm{com} / \mathrm{misc} /$ statements.dtl

\section{ACKNOWLEDGEMENTS}

The authors are grateful to B. Zeng (Centre for Sleep Health and Research, Dept of Respiratory Medicine, Royal North Shore Hospital, St Leonards, New South Wales, Australia), J. Qian (Dept of Respiratory and Sleep Medicine, St George Hospital, University of New South Wales, New South Wales), A. Ng (Dept of Respiratory and Sleep Medicine, St George Hospital), B. Liu (Dept of Orthodontics, Faculty of Dentistry, Sydney Dental Hospital, University of Sydney, New South Wales), K. Wong (Woolcock Institute of Medical Research, University of Sydney) and the sleep laboratory staff of the following institutes for their assistance: Centre for Sleep Health and Research, Dept of Respiratory Medicine, Royal North Shore Hospital, St Leonards; Dept of Respiratory and Sleep Medicine, St George Hospital. 


\section{REFERENCES}

1 Cistulli PA, Gotsopoulos H, Marklund M, et al. Treatment of snoring and obstructive sleep apnea with mandibular repositioning appliances. Sleep Med Rev 2004; 8: 443-457.

2 Ferguson KA, Cartwright R, Rogers R, et al. Oral appliances for snoring and obstructive sleep apnea: a review. Sleep 2006; 29: 244-262.

3 Chan ASL, Lee RWW, Cistulli PA. Non-positive airway pressure modalities: mandibular advancement devices/positional therapy. Proc Am Thorac Soc 2008; 5: 179-184.

4 Kushida CA, Morgenthaler TI, Littner MR, et al. Practice parameters for the treatment of snoring and obstructive sleep apnea with oral appliances: an update for 2005. Sleep 2006; 29: 240-243.

5 Gotsopoulos H, Chen C, Qian J, et al. Oral appliance therapy improves symptoms in obstructive sleep apnea: a randomized, controlled trial. Am J Respir Crit Care Med 2002; 166: 743-748.

6 Mehta A, Qian J, Petocz P, et al. A randomized, controlled study of a mandibular advancement splint for obstructive sleep apnea. Am J Respir Crit Care Med 2001; 163: 1457-1461.

7 Menn SJ, Loube DI, Morgan TD, et al. The mandibular repositioning device: role in the treatment of obstructive sleep apnea. Sleep 1996; 19: 794-800.

8 Barnes M, McEvoy RD, Banks S, et al. Efficacy of positive airway pressure and oral appliance in mild to moderate obstructive sleep apnea. Am J Respir Crit Care Med 2004; 170: 656-664.

9 Gotsopoulos H, Kelly JJ, Cistulli PA. Oral appliance therapy reduces blood pressure in obstructive sleep apnea: a randomized, controlled trial. Sleep 2004; 27: 934-941.

10 Yoshida K. Effect on blood pressure of oral appliance therapy for sleep apnea syndrome. Int J Prosthodont 2006; 19: 61-66.

11 Otsuka R, Ribeiro de Almeida F, Lowe AA, et al. The effect of oral appliance therapy on blood pressure in patients with obstructive sleep apnea. Sleep Breath 2006; 10: 29-36.

12 Naismith S, Winter V, Gotsopoulos H, et al. Neurobehavioral functioning in obstructive sleep apnea: differential effects of sleep quality, hypoxemia and subjective sleepiness. J Clin Exp Neuropsychol 2004; 26: 43-54.

13 Hsu PP, Tan BYB, Chan YH, et al. Clinical predictors in obstructive sleep apnea patients with computer-assisted quantitative videoendoscopic upper airway analysis. Laryngoscope 2004; 114: 791-799.

14 Hsu PP, Han HNC, Chan YH, et al. Quantitative computerassisted digital-imaging upper airway analysis for obstructive sleep apnoea. Clin Otolaryngol Allied Sci 2004; 29: 522-529.

15 Aboussouan LS, Golish JA, Wood BG, et al. Dynamic pharyngoscopy in predicting outcome of uvulopalatopharyngoplasty for moderate and severe obstructive sleep apnea. Chest 1995; 107: 946-951.

16 Chan A, Lee R, Ng A, et al. Nasopharyngoscopic prediction of oral appliance treatment outcome in obstructive sleep apnoea. Sleep Biol Rhythms 2007; 5: A142.

17 Chan AS, Lee RW, Ng AT, et al. Nasopharyngoscopic prediction of oral appliance treatment outcome in obstructive sleep apnea. Am J Respir Crit Care Med 2007; 175: A706.

18 Chan AS, Lee RW, Ng AT, et al. Nasopharyngoscopic prediction of oral appliance treatment outcome in obstructive sleep apnoea. Sleep Biol Rhythms 2006; 4: A46.

19 Zeng B, Ng AT, Qian J, et al. Influence of nasal resistance on oral appliance treatment outcome in obstructive sleep apnea. Sleep 2008; 31: 543-547.

20 Pitsis AJ, Darendeliler MA, Gotsopoulos H, et al. Effect of vertical dimension on efficacy of oral appliance therapy in obstructive sleep apnea. Am J Respir Crit Care Med 2002; 166: 860-864.

21 Zeng B, Ng AT, Darendeliler MA, et al. Use of flow-volume curves to predict oral appliance treatment outcome in obstructive sleep apnea. Am J Respir Crit Care Med 2007; 175: 726-730.
22 American Sleep Disorders Association. EEG arousals: scoring rules and examples: a preliminary report from the Sleep Disorders Atlas Task Force of the American Sleep Disorders Association. Sleep 1992; 15: 173-184.

23 Rechtschaffen A, Kales A. A manual of standardized terminology, techniques and scoring system for sleep stages of human subjects. Brain Information Service/Brain Research Institute, University of California, 1968.

24 Hoekema A, Stegenga B, De Bont LGM. Efficacy and co-morbidity of oral appliances in the treatment of obstructive sleep apneahypopnea: a systematic review. Crit Rev Oral Biol Med 2004; 15: 137-155.

25 Ryan CF, Love LL, Peat D, et al. Mandibular advancement oral appliance therapy for obstructive sleep apnoea: effect on awake calibre of the velopharynx. Thorax 1999; 54: 972-977.

26 Chan AS, Schwab RJ, Zeng B, et al. Mandibular advancement splints and upper airway anatomy in obstructive sleep apnea. Am J Respir Crit Care Med 2008; 177: A939.

27 Isono S, Tanaka A, Sho Y, et al. Advancement of the mandible improves velopharyngeal airway patency. J Appl Physiol 1995; 79: 2132-2138.

28 Kato J, Isono S, Tanaka A, et al. Dose-dependent effects of mandibular advancement on pharyngeal mechanics and nocturnal oxygenation in patients with sleep-disordered breathing. Chest 2000; 117: 1065-1072.

29 Eveloff SE, Rosenberg CL, Carlisle CC, et al. Efficacy of a Herbst mandibular advancement device in obstructive sleep apnea. Am J Respir Crit Care Med 1994; 149: 905-909.

30 Isono S, Tanaka A, Tagaito Y, et al. Pharyngeal patency in response to advancement of the mandible in obese anesthetized persons. Anesthesiology 1997; 87: 1055-1062.

$31 \mathrm{Ng} \mathrm{AT}$, Gotsopoulos H, Qian J, et al. Effect of oral appliance therapy on upper airway collapsibility in obstructive sleep apnea. Am J Respir Crit Care Med 2003; 168: 238-241.

32 Schwab RJ. Pro: sleep apnea is an anatomic disorder. Am J Respir Crit Care Med 2003; 168: 270-271.

33 Sanner BM, Heise M, Knoben B, et al. MRI of the pharynx and treatment efficacy of a mandibular advancement device in obstructive sleep apnoea syndrome. Eur Respir J 2002; 20: 143-150.

34 Johal A, Battagel JM, Kotecha BT. Sleep nasendoscopy: a diagnostic tool for predicting treatment success with mandibular advancement splints in obstructive sleep apnoea. Eur J Orthod 2005; 27: 607-614.

35 Marklund M, Stenlund H, Franklin KA. Mandibular advancement devices in 630 men and women with obstructive sleep apnea and snoring: tolerability and predictors of treatment success. Chest 2004; 125: 1270-1278.

36 Liu Y, Lowe AA, Fleetham JA, et al. Cephalometric and physiologic predictors of the efficacy of an adjustable oral appliance for treating obstructive sleep apnea. Am J Orthod Dentofacial Orthop 2001; 120: 639-647.

$37 \mathrm{Ng}$ AT, Qian J, Cistulli PA. Oropharyngeal collapse predicts treatment response with oral appliance therapy in obstructive sleep apnea. Sleep 2006; 29: 666-671.

38 Mayer G, Meier-Ewert K. Cephalometric predictors for orthopaedic mandibular advancement in obstructive sleep apnoea. Eur $J$ Orthod 1995; 17: 35-43.

39 Dort LC, Hadjuk E, Remmers JE. Mandibular advancement and obstructive sleep apnoea: a method for determining effective mandibular protrusion. Eur Respir J 2006; 27: 1003-1009.

40 Tsai WH, Vazquez J-C, Oshima T, et al. Remotely controlled mandibular positioner predicts efficacy of oral appliances in sleep apnea. Am J Respir Crit Care Med 2004; 170: 366-370. 